\title{
TRAGEDIA COMO FICCIÓN DE LA HISTORIA A FINALES DEL SIGLO XVIII: EL CASO DE «SOFONISBA»
}

\author{
CRISTINA BaRbolani \\ Universidad Complutense de Madrid
}

\section{Resumen}

En 1784, año en que Vittorio Alfieri concibe su Sofonisba, se publica en España una tragedia homónima de José Joaquín Mazuelo, que en el propio subtítulo se significa como *española». Sin embargo, Allison Peers la creyó una traducción de Alfieri; error corregido posteriormente por Parducci, pero tal vez admitido por inercia y causante del actual olvido de esta tragedia por parte de los especialistas. En el prólogo de esta singular versión del tema de Sofonisba el autor recuerda la importancia de la historia para la verosimilitud considerada imprescindible según la poética neoclásica- remitiendo a la historiografia como fuente del episodio trágico: menciona a Livio, a Tácito, a Rollin.

En el presente estudio, aun descartando la imitación de la tradición italiana y de Alfieri, se parte del principio común de tragedia como ficción histórica para precisar las variaciones de sensibilidad, de cultura y de gusto que sitúan la obra de Mazuelo en el contexto literario español de finales del siglo XVIII.

Existen, como es sabido, épocas que privilegian determinados temas o mitos literarios, cualesquiera que sean las causas, socioeconómicas o de otra ín- 
dole, que subyacen a su recuperación y difusión. Numerosas muestras de este fenómeno se dan a través de la traducciones y adaptaciones, objeto de estudio especial por parte de los comparatistas. Deberán estos últimos, obviamente, proceder con cautela ante la hipótesis de la traducción, verificándola en cada caso a través de un control textual riguroso. De hecho, no siempre se tratará de traducción, sino que, a veces, ocurrirá lo contrario, es decir, que dos textos supuestamente interrelacionados resulten, una vez confrontados, completamente independientes uno de otro.

Es éste el caso de dos tragedias que se presentan en un interesante doblete de título idéntico (Sofonisba) ambas del mismo año de 1784 !. Una de ellas, bastante conocida, es de Vittorio Alfieri, y la otra, prácticamente ignorada, de José Joaquín Mazuelo. A pesar de su coincidencia cronológica, singular y alentadora para la investigación, no será arbitrario, desde luego, atender a Mazuelo en mayor medida que al famoso trágico italiano ${ }^{2}$, para dar prioridad al cultivo de lo que no ha sido ni siquiera desbrozado.

De hecho, urge despejar el campo de investigación de un precipitado juicio de Allison Peers, que catalogó la obra de Mazuelo como traducción de la de Alfieri ${ }^{3}$. Es verdad que el erudito italiano Amos Parducci, alertado precisamente por la coincidencia cronologica, advirtio de este error ya en un trabajo de $1942{ }^{4}$, pero la difícil localización de este dato, o la mala fortuna, o ambas cosas han hecho que los numerosos y excelentes dieciochistas españoles no hayan reparado en ello. La razón de que Mazuelo no figure en la última y completísima historia literaria del XVIII (aunque sí aparece en la cuidada bibliografía de Aguilar Piñal) deberá buscarse tal vez en la inercia de esta equivocada consideración de traductor. Todo lo contrario; este casi desconocido dramaturgo, en efecto, hace especial hincapié en su originalidad al subtitular su Sofonisba «tragedia española», lo que en la época significaba precisamente «no traducida», con afán de distinguir su creación de la avalancha de traducciones y adaptaciones del teatro francés, inglés, alemán y, en menor me-

' En realidad, en 1784 se concibe la «Idea» de la Sofonisba de AlFIERI (publicada en 1789), mientras en la misma fecha se edita la tragedia homónima de Mazuelo.

2 Según Menéndez Pelayo, Mazuelo puede ser un anagrama; véase ParducC, Amos (1942): «Traduzioni spagnole di tragedie alfieriane», Annali alfieriani, I, pp. 41-42. Citare siempre de Sofonisba, tragedia española por Don Joseph Joaquín Mazuelo, en Madrid, por Don Antonio de Sancha, MDCCXXXIV (Biblioteca Nacional de Madrid, T 10456). De la Sofonisba de Alfieri me he ocupado recientemente en mi artículo *Tragedia contro storia nella Sofonisba alfieriana», de inminente publicación en la revista Annali alfieriani.

3 Aluson PeErs, E.(1939): «The vogue of Alfieri in Spain*, Hispanic Review, p. 140.

4 PARDUCCl, Amos (1942): «Traduzioni spagnole di tragedie alfieriane», Annali alfieriani, I, 1942, pp. 41-42. 
dida, italiano, que de algún modo suplían la escasa producción autóctona en el género trágicos.

No sólo no hay indicios para pensar que Mazuelo haya admirado o criticado la Sofonisba del trágico italiano; lo más seguro es que no tuviera la menor noticia de ella ${ }^{6}$. En su breve pero intrigante prólogo, menciona a Tito Livio, a Tácito y al francés Rollin (cuya Histoire romaine es de 1738) como a historiadores destacados en cuyos textos los lectores podrán comprobar el grado de veracidad de su propia y peculiar adaptación trágica. Habla, pues, como si fuera exclusivamente suya la iniciativa de trasiadar el episodio de Sofonisba de la historia a la tragedia.

Aunque sea aconsejable la desconfianza ante estas actitudes, parece que debe excluirse, al menos por lo que he podido averiguar, la hipotesis de un «filtro trágico» a través de versiones francesas como las de Montchrestien, Mairet o Corneille; tampoco se encuentran huellas de la adaptación que de la tragedia de Mairet hizo Voltaire en 1769. Todas estas versiones en conjunto eran deudoras de la prestigiosa Sophonisba de Trissino, considerada la primera tragedia regular europea, modelo indiscutido. Por lo que hemos podido averiguar a través de calas significativas, Mazuelo tampoco parece haber tenido en cuenta para nada al capostipite de estos antecedentes famosos. En esto coincidiría con Alfieri, quien también se alejó de Trissino. Pero la opción de Alfieri arrinconaba el prestigioso modelo trágico para tener mucho más en cuenta a Petrarca (que evoca el episodio de la desdichada reina tanto en su poema África como en sus Triumphi) ${ }^{7}$; la de Mazuelo, en cambio, parece excluir otras recreaciones literarias en su intención de conectarse directamente con la historiografía.

En cualquier caso, la cronología nos sugiere que no será inútil el estudio de las versiones de Mazuelo y de Alfieri como ficciones históricas bien diferenciadas, al menos para aclarar en alguna medida cómo la recepción de Alfieri en España, en fechas posteriores, debio de quedar condicionada por la existencia y consistencia de un anterior tratamiento teatral de los mismos temas.

En Italia el auge de la tragedia de tema histórico se debi6 intensificar por la atribución de la praetexta a Séneca, autor muy imitado a lo largo del siglo

5 A propósito de estas traducciones la escritora María Rosa Gálvez de Cabrera, al presentar sus tragedias en la Advertencia inicial habla de repidemia de predilección a los extraños y desprecio de los propios». GÁlvez DE CABrera, MARfa ROSA (1804): Obras poéticas, Madrid, Imprenta Real, p. 5.

- Recordemos que las menciones de Alfieri por parte de Napoli Signorelli, Sánchez Barbero y Leandro Fernández de Moratín son posteriores a 1784.

' Me remito a cuanto estudio detenidamente en el trabajo mencionado en la nota 1. 
XVI (Giraldi, Trissino), a lo que se sumó el impacto europeo del gran modelo trissiniano al que ya nos hemos referido. En la gran disputa renacentista sobre la credibilidad de la literatura, cuestión resuelta en gran medida con el concepto de verosimilitud, la ficción histórica ofrecía una solución aceptable y en cierto modo socorrida, que encajaba en los parámetros establecidos. Posteriormente, en el Seicento que tiende a sustraerse a toda normativa, persisten en la tragedia los temas históricos, y de hecho continúan en el siglo XVIII, cuando no sólo coexisten con los mitologicos, sino que se los considera portadores de una mayor carga ejemplar.

En España la Poética de Luzán, preceptiva clasicista marcadamente italianizante, en su afán de instaurar un género trágico «puro», recomendaba asimismo dejar los asuntos mitológicos para el melodrama y reservar los históricos para la tragedia. Siguiendo en esto a Muratori, sugiere Luzán que ha de tratarse preferiblemente de historia no contemporánea ${ }^{8}$, porque los sucesos recientes están aún vivos en la mente del pueblo y es más difícil atenerse a la verdad. La misma vocación historicista da lugar a tragedias como Virginia (1751) y Athaúlpho (1753) de Montiano, y otras como Doña María Pacheco de García Malo recientemente editada?.

Pero mientras en Italia la preceptiva clasicista se enfrentaba a una hipotética ausencia de teatro ${ }^{10}$, en España, en cambio, pretendía oponerse, a través de un planteamiento novedoso (Emilio Palacios lo define como «teatro de arte y ensayo») a una producción teatral consolidada, anclada sí en glorias pasadas, pero con rasgos preocupantes de inmovilismo: ni más ni menos que el teatro tradicional, con sus repertorios de éxito de santos, de magia, de figurón etc., que contaba con el apoyo incondicional del público (árbitro absoluto, aunque necio, en la famosa y desafortunada fórmula de Lope de Vega). Ahora bien, conviene recordar que tampoco quedaba excluida de ese teatro la presencia de la historia, en especial en alguna de sus modalidades, como por ejemplo la de la comedia heroica, inspirada a veces en asuntos reales:

Las 'comedias' historicas son aquellas, que toda la materia de su fábrica se tomó del mismo campo de la Historia, debiéndose a la bue-

${ }^{8}$ Se ha subrayado y estudiado la cuestión en PALACIOS FERNANDEZ, Emilio (1996): «Teatrow en Historia literaria de España en el Siglo XVIII, Madrid, Trotta-CSIC, p. 194.

- Garcla Malo, Ignacio (1996): Doña María Pacheco, Edición de G. Carnero, Madrid, Cátedra.

${ }^{10}$ Las propuestas de Metastasio y del propio Alfieri quisieron establecer todo un sistema ex novo; tan sólo Goldoni tuvo en cuenta, de algún modo, los repertorios ya existentes en la tradición dell' arte. 
na elección del Ingenio que toque los más curiosos puntos de ella, se funde en los más clásicos y verídicos autores ${ }^{11}$.

Con este planteamiento se defendía la tradición teatral autóctona, desprestigiada por las acusaciones de los neoclásicos (centradas en la inverosimilitud tanto como en la inmoralidad); pero también se contribuía, tal vez sin pretenderlo, a acortar las distancias entre los dos tipos de teatro. La Historia legitimaba a ambos, y también garantizaba la moralidad, pues para tal fin bastaba con escoger de ella ejemplos que mueven al heroísmo ${ }^{12}$.

En un agudo análisis de los premios literarios de la Academia Española del siglo XVIII, la estudiosa María José Rodríguez detecta la voluntad de esta importante institución, reflejo de las apetencias culturales de la época, de «recrear un teatro que acercara al público la cultura y la moral dieciochescas unidas a lo mejor de la tradición dramática española, sin apartarse por ello de los cánones del arte clásico» ${ }^{13}$. En la misma dirección apuntan las últimas investigaciones de Inmaculada Urzainqui sobre el neoclasicismo español, visto en la dialéctica fecunda de la diversidad, lejos de la «estereotipada y caricaturesca versión que de él nos legaron los románticos» ${ }^{14}$.

Si volvemos ahora a la Sofonisba de Mazuelo, su subtítulo de «tragedia española» —equivalente, como vimos, a «no traducida»- se nos antojará susceptible de una mayor resonancia, una vez que la hayamos situado en este contexto un tanto híbrido. Habrá que vincularla indudablemente, por ser tragedia, con una sensibilidad ilustrada (aunque lejos de aquella «ilustración utópica» que al parecer no existió en España, según argumenta Aguilar Piñal) y con su correspondiente poética neoclasicista. Pero también es cierto que esta Sofonisba de Mazuelo transgrede en parte los cánones de la preceptiva al uso. Por ejemplo, la unidad de lugar es bastante elástica, pues se trata de una escena única multiuso, según queda especificado tras el elenco de personajes:

"Manuel Guerrero, Respuesta a la Resolución que el Rev. P. Gaspar Díaz de la Compañia de Jesús, dio en la consulta teologica...donde se prueba lo licito de dichas comedias, y se desagravia la Cómica profesión de los graves defectos que ha pretendido imponerla... Zaragoza, 1743. Citado en Palacios, 1996: 220, $n 25$.

12 lbidem, n. 28.

13 Rodriguez SÁnchez de León, Marla José (1987); «Los premios de la Academia Española en el siglo XVIII y la estética de la época», Boletín de la Real Academia Española, LXVII, p. 414.

14 Urzainqui, Inmaculada (1996): «Aspectos de la diversidad de la crítica teatral del neoclasicismo español», en A.A.V.V., El mundo hispánico en el Siglo de las Luces, Madrid, Editorial Complutense, p. 1294. 
El Foro en el primer Acto representa tienda o de Scipión o de Masinisa, que es la de Sifax, según lo pidan los lances: en el segundo y tercer acto representa siempre campo romano, y tienda de P.C. Scipión, General del campo (pág. 6).

Tampoco se guarda el debido eslabonamiento en el sucederse de las escenas (por ejemplo, no hay continuidad entre III, 5 y III, 6), lo cual, junto a la existencia de diferentes lances, quiebra la unidad de acción. De las tres unidades la única respetada es la de tiempo: todo ocurre en un mismo día, y está anocheciendo cuando la heroína se bebe el veneno en la copa de oro que Masinisa le ha enviado ${ }^{15}$.

Cabe considerar, en cambio, como una transgresión menor la división de la tragedia en tres actos, que ciertamente estaba permitida en España ${ }^{16}$, e incluso preferida, por razones pragmáticas de eficacia ejemplar, por algunos teóricos, como Pedro Estala:

<...> esta división es más cómoda para el poeta y para el espectador, para éste porque no se interrumpe tantas veces la representación, cosa que molesta mucho, y perjudica el interés; y para aquél porque no se vería precisado a alargar con episodios importunos y con escenas frías los actos, para dar a cada uno su proporcionada cuantidad relativamente a los otros ${ }^{17}$.

En cuanto a los personajes, en el reparto inicial aparecen nueve, de los cuales cuatro son principales (Masinisa, Sifax, Scipión, Sofonisba) y cinco secundarios (P. C. Scipión, Lelio, Catón, un Oficial numida, Elisa); hay otro, Mezétulo, que no aparece en este elenco pero interviene en el acto $\mathrm{II}^{\mathbf{9}}$, con lo que sumarían diez: un número excesivo para una tragedia regular. Entre los secundarios, que generalmente relativizan las acciones heroicas, cabe destacar al Oficial numida, encargado por Masinisa de dar el mensaje de muerte a Sofonisba en estos términos:

15 Engaña al oficial portador del veneno diciéndole que lo va a arrojar al suelo; también la Sofonisba alfieriana engaña a Masinisa diciéndole que le va a dejar para él la mitad de la poción, y en cambio apura la copa.

16 Tres actos tienen, por ejemplo, el Idomeneo de Cienfuegos y el Pelayo de Quintana.

17 P. Estala, Discurso preliminar sobre la tragedia antigua y moderna, citado en PALAClos, 1996: 195. Sobre Estala véase el muy ponderado estudio de CHECA BELTRÁ, JosÉ: «La teoría de la tragedia en Estalan, en SALA VALLDANA, J. M. ed.(1995): El teatro español del siglo XVIII, Lleida, Universitat, pp. 243-263. 


\author{
$<\ldots>$ le dirás, que su esposo desgraciado \\ no hallando medios de salvar su vida \\ sin que peligre su honra, por regalo \\ le remite el veneno $<\ldots . .>$ \\ y si acaso rehusa (que no creo) \\ beber ese licor fiero y amargo \\ ábrela el pecho con la punta aguda \\ del oculto puñal; yo te lo mando, \\ obedece, y a Dios; compadeciendo \\ a tu Rey infeliz, pues ha llegado \\ el extremo fatal, de que tan sólo \\ puede piadoso ser, siendo inhumano (pág. 88)
}

solución algo expeditiva y brutal, refrendada, sin embargo, en análogas situaciones que se dan en la tragedia de la época ${ }^{18}$.

Ahora bien, fijémonos en que este Oficial numida, una vez enterado de su misión, comenta abiertamente:

¡Podráse ver exemplo más palpable

de lo que ciega el no entendido, $y$ falso

concepto del honor entre los hombres!

Pero a mí no me toca examinarlo.

Obedeciendo cumplo: y nadie puede

imputarme después como atentado

lo que es sólo lealtad al dueño mío.

Llevaréla el veneno, que a mi mano

ha fiado su esposo, en esta noche.

Lo pondré en su poder: mas si ella acaso

se resiste a beberle, eso de herirla,

perdóneme mi Rey, que yo no lo hago (págs. 88-89)

En la exclamación inicial y en la incertidumbre entre cumplir y no cumplir expresada en estos ripios (o versos, como se prefiera) asoma la misma mentalidad ilustrada que anima al Delincuente honrado de Jovellanos, a saber, esa sensibilidad que exige una revisión total del concepto bárbaro del honor hispánico. Estamos en un teatro neoclasicista, cuyo racionalismo sin embargo

18 En Idomeneo de Cienfuegos se plantea del mismo modo la supresión de un ser querido; en Don Sancho García, de Cadalso, la condesa se declara dispuesta a hacer morir a su hijo Sancho con un vaso con licor funesto servido por un criado mandado por ella (III, 8). Ambas tragedias pueden leerse en edición moderna: Cuatro tragedias neoclásicas (1981), Edición de J. Johnson, Salamanca, Almar. 
se decanta hacia la valoración de lo sensible que caracteriza el nuevo drama sentimental importado de Francia ${ }^{19}$. Al respecto cabe también subrayar la importancia de las lágrimas en esta tragedia («llorad, mujeres, si queréis vencernos» reflexiona para sí Masinisa en I, 2 al decidir salvar a Sofonisba).

Si consideramos los personajes principales, tampoco se ajustan completamente al género trágico, ni resultan demasiado ejemplares, debido a su extrema flexibilidad. Ésta se evidencia en los continuos cambios de registro, indicados en las abundantísimas acotaciones intercaladas en los parlamentos. Por poner un solo ejemplo, a lo largo de una extensa intervención (204 versos) la heroína, Sofonisba, se dirige a Masinisa con 14 acotaciones internas:

\author{
con entereza \\ hace lo que dicen los versos \\ como horrorizada \\ desde aquí con caricia \\ súplicas tiernas \\ con despego \\ con rabia \\ con entereza \\ con terneza \\ se arrodillan las dos 'ella y Elisa, su confidente' y lloran las le- \\ vanta Masinisa \\ ruido de caxas y de pifianos \\ apresurada, y fuerte \\ con denuedo y fortaleza (I, 2; pp. 21-28)
}

Esta abundancia de indicaciones destinadas a la escenificación contrasta claramente con la sobriedad y escasez de ellas en los personajes alfierianos, caracterizados por una aparente rigidez e inmutabilidad; el proceso que Alfieri condensa en su interior, en Mazuelo queda confiado a códigos extratextuales que lo hacen evidente.

Habrá que tener en cuenta estas anomalías al situar la tragedia de Mazuelo dentro de la dramaturgia neoclásica, cuyas novedosas propuestas (no lo olvidemos) aparecían en plena crisis del antiguo ideal heroico del teatro tradicional español ${ }^{20}$. Sólo así podremos explicarnos las contradicciones internas de

${ }^{19}$ Es importante al respecto la traducción que emprende Luzán del drama lagrimoso de Nivelle de la Chaussée. Véase BARBOLANI, CRISTINA (1991): «La razón contra la moda: reflexiones sobre Luzán traductor» en LAFARGA, FRANCISCO (ed.): Traducción y adaptación cultural: EspañaFrancia, Universidad de Oviedo, pp. 551-559.

${ }^{20}$ Crisis muy agudamente analizada en ANDIOC, RENE (1987): Teatro y sociedad en el Madrid del siglo XVIII, Madrid, Castalia. Andioc conecta muy acertadamente el nuevo teatro con el 
la Sofonisba mazueliana, pues esta crisis atañe también al héroe neoclásico ilustrado.

Ambigua y crítica resulta, en efecto, la posición de Mazuelo respecto al protagonista masculino, Masinisa. Este, después de haber reprobado a Sifax por haber caído en las redes de Sofonisba, a su vez experimenta como víctima los efectos de estos torpes amores ${ }^{21}$, tópico ya prestigiado en la Numancia de Cervantes, en la que los soldados de Escipión aparecen debilitados en sus virtudes guerreras por el placer y la ociosidad. Asimismo Masinisa queda «vencido» por la cautiva hermosa; aunque luego la quitará de en medio, como hemos visto, sin demasiados escrúpulos, apoyándose en la casuística del honor. Esta ambigüedad podemos considerarla en consonancia y analogía con la más conocida de las tragedias españolas del XVIII, es decir la Raquel de García de la Huerta. Al igual que en Huerta, tampoco en Mazuelo queda claro lo que el autor piensa realmente de su heroína. Por una parte parece seguir el antifeminismo ilustrado ${ }^{22}$, en tanto en cuanto nos presenta el amor de ella por Masinisa como ejemplarmente femenino, es.decir, marcado por la máxima sumisión, hasta aceptar la muerte que le ha sido ordenada. Al recibir el veneno, ella no medita demasiado:
Razón será que cumpla sus preceptos
la que tanto te amo: mi infausta estrella me obliga a obedecer sin repugnancia
de mi esposo infeliz la orden funesta (pág. 101) ${ }^{23}$.

Sin embargo, a pesar de que esta actitud quede recalcada como un deber de fidelidad y sumisión, esto no impide el que se cuestione, en cierto modo, la hazaña del suicidio de Sofonisba al rodearlo de un halo especial de ternura y sobre todo al ponderar la crueldad implícita en su sacrificio cumplido en aras de la razón de estado.

Considero muy importante este último punto, aunque aquí cabe hacer tan sólo una breve alusión a la forma en que aparece en la tragedia. Masinisa al enviar a Sofonisba el veneno le recomienda a través del oficial numida:

\footnotetext{
«despotismo ilustrado» (fórmula ésta que sigue siendo rechazada por el estudioso Aguilar Piñal como un contrasentido). 10 y p.16.

${ }^{21}$ Esta expresión aparece tanto en boca de Escipión como en la de Masinisa en el acto I, p.

${ }^{22}$ Sobre la obsesión de igualdad de las mujeres reprobada por Moratín, quien desconfiaba de los ejemplos de heroismo femenino, véase ANDIOC 1987: 503-504.

23 Nada más opuesto a Alfieri, por cierto, en cuya tragedia la heróna se suicida en contra de los tentativos de salvarla tanto de parte del marido Sifax como del amante Masinisa.
} 


\begin{abstract}
$<\ldots>$ que se muestre grande, y obediente a mi voz, y que aguardando quedo las tristes nuevas de su muerte, para seguirla donde resguardados de feroces insultos de mortales, así ella como yo mostrar podamos los subidos quilates de un afecto que turba aquí la sinrazón de estado (III, p. 88)
\end{abstract}

Esta paradojica expresión condenatoria, de origen quevedesco, es un eco lejano de una polémica antimaquiavélica que venía arrastrándose desde hacía siglos; ahora bien, resulta de interés destacar asimismo hasta qué punto la razón de estado aparece despreciada en otras tragedias dieciochescas. En la ya mencionada Raquel, el rey Alfonso se dirige a Manrique confesando lo que le pesa su condición de rey: envidia al villano porque en su caso «nunca de estado la razón tirana/tanto bien, tanta gloria me impidiera», es decir que, de ser villano, la razón de estado no sería un obstáculo a su amor por la bella judía. También en Don Sancho García, de Cadalso, Almanzor quiere convencer a la condesa para que sacrifique a su hijo con estas palabras:

A la razón de estado no hay razones que superiores sean, ni hay ideas que pesen más <...>

a las que la Condesa replica: «Tirano!» ${ }^{24}$.

Para Mazuelo Sofonisba tiene la aureola propia de las víctimas, pero su muerte inevitable, histórica y ejemplar, debe ser dispuesta por quien la ama: se rescata así a Masinisa, que corre el peligro de resultar escasamente heroico ${ }^{25}$. Masinisa de hecho baraja la idea de seguirla a ella en el suicidio, pero acaba descartando esta solución, porque su deber es el de quedar para «llorar su muerte, hacerla sus exequias», según reflexiona al final del acto II $^{2}$, con prolexis del desarrollo de la tragedia:

${ }^{24}$ Cito de Cuatro tragedias neoclásicas, 1981, p. 190.

29. En un largo soliloquio (II, 1, pp. 54-55) Masinisa se presenta a sí mismo como debilitado en su virilidad por la pasión: 


\section{Llórela yo, mas no se diga nunca que vivir la dexé para su afrenta. Así cumplo conmigo, con su fama, burlo también de Roma la soberbia, y puedo disfrutar del triste gusto de esmerarme de suerte en sus exequias que admire el mundo lo que amé a una esposa a quien me ve adorar después de muerta $<\ldots .>$ (II, pág. 73)}

Esto, que a un lector de nuestro siglo puede parecer un claro rasgo de cinismo con ribetes cómicos, se ampara, sin embargo, en prestigiosos antecedentes literarios que le pueden llegar a Mazuelo por dos vías: por una parte la tragedia regular de Trissino (tal vez en reelaboraciones francesas) cuyo protagonista insiste especialmente en las finales onorate esequie ${ }^{26}$, y por otra la tradición necrófila española cuyo mejor ejemplo es Reinar después de morir de Luis Vélez de Guevara. El drama de Inés de Castro, en efecto, seguía gozando de los favores del público dieciochesco: se representó en noviembre de este mismo año de 1784 en el Coliseo de la $\mathrm{Cruz}^{27}$, y su prestigio fue incrementado también al ser objeto de adaptaciones francesas (tal era el drama de La Motte titulado, precisamente, Inés de Castro). A este peculiar entrecruzarse de necrofilia barroca y planctus propio de la tragedia clasicista, se añaden y mezclan sin duda las ya aludidas lágrimas «modernas», propias del nuevo drama sentimental burgués. El análisis de un llanto tan complejo excedería el espacio de esta breve nota, ceñida a subrayar algunos aspectos híbridos significativos de una tragedia poco conocida, de cuyo autor, por ahora, lo ignoramos todo. Esta Sofonisba, claro está, no destaca especialmente por su calidad literaria -reconozcamos que lo mismo ocurre también con tragedias de autores famosos de la época- pero merece sin duda una lectura más atenta. Valdrá la pena tenerla en cuenta para futuros estudios, a partir del dato indiscutible de que no es en absoluto una traducción de Alfieri.

26 Trissino, Giangiorgio (1977): Sophonisba, Ed. de M. Ariani, Torino, Einaudi, p. 77.

${ }^{27}$ Consta en el Memorial literario instructivo y curioso de la Corte de Madrid, 1784 (19, 20 y 21 de noviembre). 